\section{BMJ Open Respiratory Research}

\title{
Underlying contributing conditions to breathlessness among middle-aged individuals in the general population: a cross-sectional study
}

\author{
Jacob Sandberg (D) ,' Magnus Ekström (D) ,' Mats Börjesson, ${ }^{1,3,4}$ \\ Göran Bergström, ${ }^{2,5}$ Annika Rosengren, ${ }^{2,3}$ Oskar Angerås, ${ }^{2,6}$ Kjell Toren ${ }^{7}$
}

\section{ABSTRACT}

Introduction Breathlessness is common in the general population and associated with poorer health. Prevalence, frequencies and overlap of underlying contributing conditions among individuals reporting breathlessness in the general population is unclear. The aim was to evaluate which conditions that were prevalent, overlapping and associated with breathlessness in a middle-aged general population.

Method Cross-sectional analysis of individuals aged 5065 years in the Swedish CArdioPulmonary biolmage Study pilot. Data from questionnaire, spirometry testing and fitness testing were used to identify underlying contributing conditions among participants reporting breathlessness (a modified Medical Research Scale (mMRC) score $\geq 1$ ). Multivariate logistic regression was used to identify independent associations with breathlessness.

Results 1097 participants were included; mean age 57.5 years, $50 \%$ women and $9.8 \%(n=108)$ reported breathlessness (mMRC $\geq 1$ ). Main underlying contributing conditions were respiratory disease $(57 \%)$, anxiety or depression (52\%), obesity (43\%) and heart disease or chest pain (35\%). At least one contributing condition was found in $99.6 \%$ of all participants reporting breathlessness, while two or more conditions were present in $66 \%$.

Conclusion In a middle-aged general population, the main underlying contributing conditions to breathlessness were respiratory disease, anxiety or depression, obesity and heart disease or chest pain with a high level of overlap.

\section{INTRODUCTION}

Check for updates

(C) Author(s) (or their employer(s)) 2020. Re-use permitted under CC BY-NC. No commercial re-use. See rights and permissions. Published by BMJ.

For numbered affiliations see end of article.

Correspondence to Dr Jacob Sandberg; jacob.sandberg@gmail.com
Breathlessness is defined as the subjective experience of breathing discomfort and affects 10\%-25\% of middle aged and elderly people in the general population. ${ }^{1-4}$ Breathlessness is the main reason for $1 \%-3.9 \%$ of primary care consultations across several European countries and is also present in a high proportion of people seeking care for other reasons. ${ }^{5}{ }^{6}$ Presence of self-reported breathlessness, often measured using the modified Medical Research council (mMRC) scale, indicates a poorer prognosis, lower

\section{Key messages}

What is the frequency and overlap of underlying conditions contributing to breathlessness in the general population?

- The most common underlying conditions contributing to breathlessness is respiratory disease, anxiety or depression, obesity and heart disease with a large degree of overlap.

- This study is the first population-based study on contributing causes to breathlessness and presents new information on the relationships between breathlessness and underlying contributing condition.

quality of life, higher rate of hospitalisation and is strongly associated with mortality. ${ }^{5}$-14

Several conditions have been shown to cause breathlessness. Pulmonary disease cause breathlessness through several mechanisms such as increased central respiratory neural drive, vagal influences on respiratory sensation and afferent inputs from respiratory muscles. ${ }^{15} 16$ Breathlessness is also caused by heart diseases such as heart failure, valvular disease and ischaemic heart disease. ${ }^{1517}$ Obese individuals in the community have increased risk of activity-related breathlessness. ${ }^{18}$ It is suggested that the increased breathlessness due to obesity is caused largely by the extra workload and the following extra respiratory demand. ${ }^{19}{ }^{20}$ Low aerobic fitness may contribute to breathlessness ${ }^{1521}$ but has been shown to correlate poorly with reported breathlessness during exercise testing. ${ }^{22}$ However, the relationship between aerobic fitness, obesity and breathlessness has not been explored using standardised testing. Psychological conditions such as anxiety or depression are more common in individuals reporting breathlessness and may also contribute to breathlessness through reduced 
respiratory sensory gating and increased awareness of breathing problems. ${ }^{23}$

Although the prevalence and severity of breathlessness has been assessed at the population level, knowledge on the frequencies of underlying conditions contributing to breathlessness in the general public is scarce. One previous study, using self-report, examined the underlying contributing conditions and showed that respiratory disease was the most common entity, reported by $62 \%$ of participants with breathlessness. ${ }^{24}$ Other studies examining the underlying contributing conditions among breathless individuals performed in hospital and pulmonary clinical settings showed that $53 \%$ of breathless individuals was given a respiratory diagnosis, and $16 \%$ was attributed to heart disease, the remaining $31 \%$ had other underlying conditions. ${ }^{15}$

Diagnoses known to cause breathlessness often coexists. Most notably chronic obstructive pulmonary disease (COPD) and heart disease as they share risk factors, but also COPD and anxiety or depression as well as COPD and obesity. ${ }^{25}$ The overlap of contributing causes of breathlessness in a general population has not been systematically evaluated.

The primary aim of the present paper was to evaluate which conditions that were prevalent and overlapping as well as the frequency of these conditions among individuals reporting breathlessness in a middle-aged general population. Secondary aims were to explore associations between underlying contributing conditions and breathlessness and to explore the relationship between obesity and breathlessness when adjusting for fitness level.

\section{METHODS}

\section{Design and population}

This was a cross-sectional analysis of individuals aged 50-65 years in the Swedish Cardiopulmonary bioImage Study (SCAPIS) pilot. This was the pilot part of the larger SCAPIS cohort that was designed as a prospective observational study of a randomly selected sample from the general population. The study design is detailed elsewhere. $^{26} 27$ Participants were resident in Gothenburg, Sweden, in 2012 and identified from the population registry. They were recruited both from areas with high and with low socioeconomic status. Exclusion criteria for the present analysis were inability to walk for other reason than breathlessness and missing data on mMRC.

\section{Assessments and definitions}

Breathlessness was assessed using the mMRC scale, which is frequently used to measure the physical disability and functional impact of breathlessness in population studies. ${ }^{728-30}$ The mMRC is a self-administered assessment of exertional breathlessness categorised as: 0 (not troubled by breathlessness except on strenuous exercise), 1 (short of breath when hurrying or walking up a slight hill), 2 (walks slower than contemporaries on the level because of breathlessness or has to stop for breath when walking at own pace), 3 (stops for breath after walking $100 \mathrm{~m}$ or after a few minutes on the level) and 4 (too breathless to leave the house or breathless when dressing or undressing). In the present study, breathlessness was defined as an mMRC score of 1 or more. ${ }^{14} 18$

Spirometry testing was used to assess the presence of chronic airflow limitation (defined as postbronchodilator forced expiratory volume in $1 \mathrm{~s}\left(\mathrm{FEV}_{1}\right) /$ forced vital capacity (FVC) below the fifth percentile (lower limit of normal (LLN)) or restriction (total lung capacity $<\mathrm{LLN}$ ). Spirometry including plethysmography was performed using Jaeger Master Screen equipment (Hoechberg, Germany) according to European Respiratory Society/ American Thoracic Society (ERS/ATS) standards. ${ }^{31}$ For $\mathrm{FEV}_{1}$ and $\mathrm{FVC}$, the postbronchodilator values $15 \mathrm{~min}$ after inhalation of $400 \mu \mathrm{g}$ of salbutamol was used. All lung function measures were expressed as absolute value and percentage of predicted using European references. ${ }^{32-35}$

The categorisation of lung impairment was performed according to previous studies and ERS/ATS guidelines. ${ }^{3136}$ Self-report was used for COPD, asthma, chronic bronchitis (self-reported productive cough for at least 3 months during each of the two last years) or other respiratory disease. Respiratory disease was defined as presence of any of COPD, asthma, chronic bronchitis, other respiratory disease or chronic airflow limitation or restriction on spirometry testing. Heart disease was assessed by self-report of physician diagnosed myocardial infarction, having had a percutaneous coronary intervention, coronary bypass or valvular surgery, presence of atrial fibrillation/flutter on ECG or self-reported angina pectoris (defined as answering yes to the question 'do you experience chest pain when walking fast or uphill?' or 'do you experience chest pain when walking on the level at normal walking speed?' and answering yes to the question 'Does the chest pain disappear if you stop or slow down?).

Measurement of weight and height were used to calculate the body mass index (BMI) (weight $(\mathrm{kg}) /$ height $\left.(\mathrm{m})^{2}\right)$. Overweight was defined as having a BMI between 25.0-29.9 and obesity as having 30 or higher. Obesity was chosen as a main factor as it was considered a more specific cause of breathlessness than overweight as almost half of this population was overweight. ${ }^{18}$

Aerobic fitness was assessed using a submaximal cycle test (the Ekblom-Bak test) of maximum oxygen uptake $\left(\mathrm{VO}_{2} \max \right)$ and assessed according to normal values for age and gender as performed and validated in previous studies. ${ }^{3738}$ Participants with a diagnosed heart condition or taking beta-adrenergic blockers were excluded from the fitness testing and additional subjects did not participate due to various other reasons such as pain, obesity, perceived inability to perform the test or ongoing illness $(n=441)$. A subgroup of 656 individuals remained for assessment with the fitness test. Low fitness was defined as having a $\mathrm{VO}_{2}$ max of $28 \mathrm{~mL} / \mathrm{kg} / \mathrm{min}$ or less for men aged 50-59 years, $23 \mathrm{~mL} / \mathrm{kg} / \mathrm{min}$ or less for men aged 60 years or higher, $26 \mathrm{~mL} / \mathrm{kg} / \mathrm{min}$ or less for women aged 
$50-59$ years or $22 \mathrm{~mL} / \mathrm{kg} / \mathrm{min}$ or less for women aged 60 years or higher. ${ }^{37}$

Anxiety was defined as the participant answering 'yes, continuously during the last year' to the question 'With stress we mean feeling tense, agitated, nervous, anxious or having trouble with sleep because of the situation at work or at home, have you experienced this?', this method has been used in several previous publications. ${ }^{39}$

Depression was assessed by asking if the participant had felt sad, blue or depressed for 2 weeks or more in a row in the last 12 months, and if yes, also answering yes to five out of seven yes or no questions concerning losing interest in things, feeling tired or low on energy, gaining or losing weight, trouble falling asleep, trouble concentrating, thoughts of death and feelings of worthlessness. The questionnaire questions concerning depression are an adaptation of the short form Composite International Diagnostic Interview for the Diagnostic and Statistical Manual of Mental Disorders version 5 I questionnaire. ${ }^{40}$

Anaemia was categorised as having a haemoglobulin level in blood of lower than $110 \mathrm{~g} / \mathrm{L}$, which is the cut-off level for moderate anaemia according to the WHO. ${ }^{41}$

\section{Statistical analyses}

Patient characteristics were tabulated by presence of breathlessness $(m M R C \geq 1)$ and displayed using frequencies and percentages for categorical data as well as mean and SD for continuous variables. ${ }^{6} 1517$

Respiratory disease (COPD, asthma, chronic bronchitis, other respiratory disease, chronic airflow limitation or restriction on spirometry), heart disease or chest pain (heart failure, atrial fibrillation, angina pectoris and coronary heart disease), obesity, anxiety and depression were selected as underlying contributing conditions to breathlessness. These were selected based on subject matter knowledge from mechanistic and population studies. ${ }^{1-3} 2442-47$

The associations between breathlessness and the possibly underlying contributing conditions were analysed using multiple logistic regression, with associations expressed as ORs with 95\% CIs. The conditions were analysed both separately and merged into the main underlying condition groups (respiratory disease, heart disease or chest pain, obesity and anxiety or depression) in accordance with the categories in the study by Johnson et $a .^{24}$ Associations were analysed and controlled separately for possible confounding from age, sex, BMI (for all except obesity) socioeconomic status and smoking status and shown in table 1. Regression analysis was not performed on variables with too few cases (atrial fibrillation, coronary heart disease and anaemia). To look for independent associations between the conditions and breathlessness, we added a second analysis model as shown in table 2. Chronic airflow limitation, chronic bronchitis and angina pectoris were chosen to be included as they were deemed to be the most specific and most objective measures from the larger groups.

\begin{tabular}{|c|c|c|}
\hline \multirow[b]{2}{*}{ Factor } & \multicolumn{2}{|c|}{ mMRC $\geq 1$ versus 0} \\
\hline & $\begin{array}{l}\text { Crude OR } \\
(95 \% \mathrm{Cl})\end{array}$ & $\begin{array}{l}\text { Adjusted OR } \\
(95 \% \mathrm{Cl})^{*}\end{array}$ \\
\hline Respiratory disease & 2.5 (1.6 to 3.7 ) & 2.0 (1.3 to 3.2 ) \\
\hline $\begin{array}{l}\text { Chronic airflow } \\
\text { limitation }\left(\mathrm{FEV}_{1}<\mathrm{LLN}\right)\end{array}$ & 2.4 (1.4 to 3.9$)$ & 1.8 (1.0 to 3.1$)$ \\
\hline Asthma & 4.0 (2.4 to 6.6$)$ & 3.0 (1.7 to 5.2$)$ \\
\hline COPD & 10.1 (4.4 to 23.2) & 7.4 (3.0 to 18.5$)$ \\
\hline Chronic bronchitis & 3.8 (2.2 to 6.5$)$ & 3.6 (2.0 to 6.6 ) \\
\hline $\begin{array}{l}\text { Heart disease or chest } \\
\text { pain }\end{array}$ & 8.3 (5.1 to 13.5$)$ & 6.9 (4.0 to 11.9$)$ \\
\hline Angina pectoris & $10.4(6.1$ to 17.8$)$ & 9.3 (5.1 to 17.2$)$ \\
\hline Heart failure & 7.7 (2.0 to 29.0 ) & 6.6 (1.3 to 33.3$)$ \\
\hline Anxiety or depression & 3.5 (2.4 to 5.3$)$ & $3.3(2.1$ to 5.1$)$ \\
\hline Anxiety & 2.4 (1.6 to 3.7$)$ & 2.2 (1.4 to 3.5$)$ \\
\hline Depression & 4.3 (2.7 to 7.0$)$ & 3.3 (2.0 to 5.4$)$ \\
\hline \multicolumn{3}{|l|}{ Other } \\
\hline Obesity† & 3.1 (2.0 to 4.7 ) & 2.7 (1.8 to 4.2 ) \\
\hline
\end{tabular}

OR and $95 \%$ Cls.

Analysed as separate variables.

*Adjusted for age, sex, body mass index (BMI), socioeconomic status and smoking status, as applicable. Obesity $=\mathrm{BMI}>30$; $\mathrm{BMI}<30$ is the reference value.

†Not adjusted for BMI.

COPD, chronic obstructive pulmonary disease; $\mathrm{FEV}_{1}$, forced expiratory volume for $1 \mathrm{~s}$; LLN, lower limit of normal; mMRC, modified Medical Research Council.

Anxiety, depression and obesity were also included, and all the factors were added into the same model together with the background variables, age, sex, socioeconomic status, smoking status and physical fitness and presented in table 2.

No values were imputed, and analyses were by complete cases only. Analysis of concurrent conditions were performed by tabulation and visualised using Venn diagram software. ${ }^{48}$ Missing data were visualised in table 3. Statistical significance was defined as two-sided $p$ value $<0.05$. Statistical analyses were performed with Stata V.14.2.

\section{RESULTS}

After excluding participants with inability to walk for other reason than breathlessness $(\mathrm{n}=14 ; 1.2 \%), 1097$ participants were included. Baseline characteristics, spirometry values and underlying contributing conditions of the participants are shown in table 3 . The mean age was 57.5 ( $\mathrm{SD} 4.4$ ) years and $57 \%$ were former or current smokers. Overweight and obesity were highly prevalent in this population and $68 \%(\mathrm{n}=749)$ had a BMI $>25$. Low aerobic fitness was present among 77 out of the 656 assessed with fitness testing $(12 \%)$. 
Table 2 Multivariable analysis of independent associations between underlying contributing conditions and breathlessness

\begin{tabular}{ll}
\hline & $\begin{array}{l}\text { mMRC } \geq \mathbf{1} \\
\text { versus } \mathbf{0}\end{array}$ \\
\cline { 2 - 2 } Factor & $\begin{array}{l}\text { Adjusted } \mathbf{O R} \\
\mathbf{( 9 5 \% ~} \mathbf{C l})^{*}\end{array}$ \\
\hline Chronic airflow limitation (FEV $1<$ LLN) & $1.6(0.8$ to 3.1$)$ \\
\hline Chronic bronchitis & $2.4(1.2$ to 4.8$)$ \\
\hline Angina pectoris & $7.5(3.9$ to 14.7$)$ \\
\hline Anxiety & $1.3(0.7$ to 2.3$)$ \\
\hline Depression & $2.1(1.2$ to 3.9$)$ \\
\hline Obesity & $3.7(2.2$ to 6.1$)$ \\
\hline
\end{tabular}

OR and $95 \%$ Cls.

*Adjusted for age, sex, socioeconomic status, smoking status, aerobic fitness and all other factors in table. Obesity=body mass index $(\mathrm{BMI})>30$; $\mathrm{BMI}<30$ is the reference value.

$\mathrm{FEV}_{1}$, forced expiratory volume for $1 \mathrm{~s}$; LLN, lower limit of normal; mMRC, modified Medical Research Council.

Breathlessness was present in 9.8\% (n=108) of participants and more common among women than men and among participants with low Socioeconomic status (SES), with higher BMI, lower aerobic fitness and among people with higher smoking exposure (table 3).

The main underlying contributing conditions among individuals reporting breathlessness were respiratory disease $(57 \%)$ followed by anxiety or depression $(51 \%)$, obesity $(43 \%)$ and heart disease or chest pain $(35 \%)$ as shown in table 3 . Four participants with breathlessness $(0.4 \%)$ were not categorised as having any known contributing condition.

Overlap of underlying contributing conditions to breathlessness was common; two or more concurrent conditions were present in $66 \%$ of the participants reporting breathlessness (figure 1A-C). Respiratory disease and anxiety or depression was the most common combination $(57 \%$ of individuals reporting breathlessness) followed by respiratory disease and obesity (50\% of individuals reporting breathlessness).

All main conditions were more prevalent in the groups reporting breathlessness compared with the group without breathlessness. Associations between the main underlying contributing conditions and breathlessness are shown both crude and adjusted for age, sex BMI, socioeconomic status and smoking status in table 1. Breathlessness was associated with several respiratory conditions such as COPD (OR 7.4; 95\% CI 3.0 to 18.5), asthma (OR 3.0; 95\% CI 1.7 to 5.2), chronic bronchitis (OR 3.6; 95\% CI 2.0 to 6.6) and having chronic airflow limitation on spirometry (OR 1.8; 95\% CI 1.0 to 3.1). It was also associated with heart disease, mainly angina pectoris (OR 9.3; 95\% CI 5.1 to 17.2 ) and with obesity (OR 2.7; 95\% CI 1.8 to 4.2 ), anxiety (OR 2.2; $95 \%$ CI 1.4 to 3.5 ) and depression (OR 3.3; 95\% CI 2.0 to 5.4) (table 1).
The final model is shown in table 2. The factors remaining as independently associated with breathlessness after adjusting for background variables (age, sex, socioeconomic status and pack-years) as well as the other factors in table 2 were chronic bronchitis (OR 2.4; $95 \%$ CI 1.2 to 4.8 ), angina pectoris (OR 7.5; $95 \%$ CI 3.9 to 14.7 ), obesity (OR 3.6; 95\% CI 2.2 to 6.1) and depression (OR $2.1 ; 95 \%$ CI 1.2 to 3.9 ). Obesity was independently associated with breathlessness even after additional adjustment for aerobic fitness level $(\mathrm{n}=656)$ (OR 3.4; $95 \%$ CI 1.5 to 76).

\section{DISCUSSION \\ Main findings}

The main underlying contributing condition among middle-aged individuals reporting breathlessness were respiratory disease $(57 \%)$ followed by anxiety or depression $(51 \%)$, obesity $(43 \%)$ and heart disease or chest pain $(35 \%)$. Overlap was common with $66 \%$ having two or more concurrent contributing conditions. Obesity was associated with reported breathlessness even after adjusting for aerobic fitness level.

\section{What this study adds}

The present study adds to the previous knowledge in several ways. First, it describes the frequency of conditions among breathless individuals in the general population. Second, it is performed in a general population and uses both spirometry and fitness testing in addition to selfreport. Third, we showed an association between obesity and breathlessness, which remained even after adjusting for aerobic fitness level which, to the author's knowledge, has not been controlled previously in a general population. ${ }^{18} 49$ This finding suggests that the high weight itself is an important factor for increased breathlessness even among obese individuals with normal aerobic fitness levels.

Several previous studies have reported similar findings of pulmonary disease as the most common entity contributing to breathlessness followed by heart disease and obesity. ${ }^{61524}$ Anxiety, depression and respiratory disease coexisted to a very large degree in our study supporting previous results. ${ }^{5051}$

We found a high degree of overlap between conditions contributing to breathlessness, more than what was reported in the study by Pratter et al which, however, was performed on a population of care seeking individuals. Our findings are in line with the literature on diagnoses coexisting with COPD, where high rates of concurrent COPD and either coronary heart disease $(30 \%)$, heart failure $(63 \%)$ or depression $(20 \%-60 \%)$ were reported. ${ }^{1525}$ In our study, there was a high prevalence of obesity and of anxiety or depression among participants reporting breathlessness, which is one explanation for the high proportion of individuals with several concurrent conditions. ${ }^{15}$ 
Table 3 Characteristics of 1097 people from the middle-aged general population by presence of breathlessness

\begin{tabular}{|c|c|c|c|}
\hline Variable & $\begin{array}{l}\text { With breathlessness } \\
(\mathrm{mMRC} \geq 1) \\
\mathrm{n}=108\end{array}$ & $\begin{array}{l}\text { Without breathlessness } \\
(\mathrm{mMRC}=0) \\
\mathrm{n}=989\end{array}$ & $P$ value \\
\hline Age, mean years $(\mathrm{SD})$ & $59.1(4)$ & $57.5(4)$ & $<0.001$ \\
\hline Female, n (\%) & $71(66)$ & $477(48)$ & 0.001 \\
\hline Low socioeconomic status, $\mathrm{n}(\%)$ & $80(74)$ & $461(47)$ & $<0.001$ \\
\hline $\mathrm{BMI}, \mathrm{kg} / \mathrm{m}^{2}$, mean (SD) & $30.2(6)$ & $26.9(4)$ & $<0.001$ \\
\hline Pack years of smoking, mean years (SD) & $16.9(30)$ & $9.3(13.6)$ & $<0.001$ \\
\hline Smoking status, $\mathrm{n}(\%)$ & & & 0.069 \\
\hline Never & $37(34)$ & $441(45)$ & \\
\hline Current & $26(24)$ & $169(17)$ & \\
\hline Former & $45(42)$ & $379(38)$ & \\
\hline Fitness- Ekblom-Bak (mL/min/kg), mean (SD) (missing=441) & $30.7(7)$ & $35.4(7)$ & $<0.001$ \\
\hline Low aerobic fitness ${ }^{*}, \mathrm{n}(\%)$ (missing=441) & $14(33)$ & $63(10)$ & $<0.001$ \\
\hline $\mathrm{FEV}_{1}, \mathrm{~L}(\mathrm{SD})($ missing $=15)$ & $2.6(0.6)$ & $3.3(0.75)$ & $<0.001$ \\
\hline $\mathrm{FEV}_{1}, \%$ of predicted (SD) & $84(23)$ & $102(23)$ & $<0.001$ \\
\hline FVC, L (SD) (missing=15) & $3.5(0.8)$ & $4.2(1)$ & $<0.001$ \\
\hline FVC, \% of predicted (SD) & $88(24)$ & $103(24)$ & $<0.001$ \\
\hline $\mathrm{FEV}_{1} / \mathrm{FVC}(\mathrm{SD})$ (missing=22) & $0.75(0.1)$ & $0.78(0.6)$ & $<0.001$ \\
\hline $\mathrm{FEV}_{1} / \mathrm{FVC}, \%$ of predicted (SD) (missing $\left.=22\right)$ & $93(14)$ & $98(8)$ & $<0.001$ \\
\hline Chronic airflow limitation (FEV1 <LLN), n (\%) (missing=22) & $24(23)$ & $109(11)$ & 0.001 \\
\hline Restriction (TLC <LLN) (missing=45) & $9(9.1)$ & $68(7.1)$ & 0.48 \\
\hline Respiratory disease, $n(\%)$ (missing=34) & $58(57)$ & $341(35)$ & 0.001 \\
\hline Asthma, $\mathrm{n}(\%)$ (missing=15) & $26(24)$ & $72(7)$ & $<0.001$ \\
\hline COPD, n (\%) (missing=15) & $12(11.2)$ & $12(1.2)$ & $<0.001$ \\
\hline Chronic bronchitis, $n$ (\%) (missing=41) & $21(20)$ & $60(6)$ & $<0.001$ \\
\hline Heart disease or chest pain, $n(\%)($ missing $=47)$ & $35(35)$ & $59(6)$ & $<0.001$ \\
\hline Atrial fibrillation/flutter, $\mathrm{n}(\%)$ (missing=17) & $2(2)$ & $7(0.7)$ & 0.19 \\
\hline Angina pectoris, $n(\%)$ (missing=22) & $30(30)$ & $38(4)$ & $<0.001$ \\
\hline Coronary heart disease, $\mathrm{n}(\%)$, (missing $=21$ ) & $4(4)$ & $15(1.5)$ & 0.24 \\
\hline Heart failure, $n(\%)$ (missing=29) & $3(3.8)$ & $5(0.5)$ & 0.094 \\
\hline Anxiety or depression, $n(\%)$ (missing=9) & $56(52)$ & $228(23)$ & $<0.001$ \\
\hline Anxiety, $\mathrm{n}(\%)$ (missing=22) & $39(36)$ & $188(19)$ & $<0.001$ \\
\hline Depression, $\mathrm{n}(\%)$ (missing=32) & $33(31)$ & $89(9)$ & $<0.001$ \\
\hline Anaemia, $\mathrm{n}(\%)$ (missing $=8$ ) & $1(1)$ & $9(1)$ & 0.96 \\
\hline Obesity, n (\%) & $46(43)$ & $190(19)$ & $<0.001$ \\
\hline
\end{tabular}

Obesity $=\mathrm{BMl}>30$.

*Subcohort with measured exercise capacity using the Ekblom-Bak test $(n=656)$, defined as having a score of 28 or less for men aged $50-59$ years, 23 or less for men aged 60 years or higher, 26 or less for women aged 50-59years or a score of 22 or lower for women aged 60 years or higher.

$\mathrm{BMI}$, body mass index; COPD, chronic obstructive pulmonary disease; $\mathrm{FEV}_{1}$, forced expiratory volume during $1 \mathrm{~s}$; FVC, functional vital capacity; LLN, lower limit of normal; mMRC, modified Medical Research Council; TLC, total lung capacity.

Angina pectoris was shown to be strongly and independently associated with breathlessness, this might in part be explained by the questioning and symptomatology that is similar to the mMRC questions. Chronic airflow limitation was however not independently associated with breathlessness. This might be explained by the fact that we found many participants with pathology on spirometry but without both self-reported disease and no breathlessness on the mMRC. Problems with the mMRC scale in detecting symptoms in this group has been previously discussed and includes the fact that mMRC measures the functional impact of breathlessness that might not be the same as pathological breathlessness. Also, the mMRC might not register symptoms at all in the case of high inactivity, which is common in many populations worldwide, including the present one. ${ }^{352}$ 

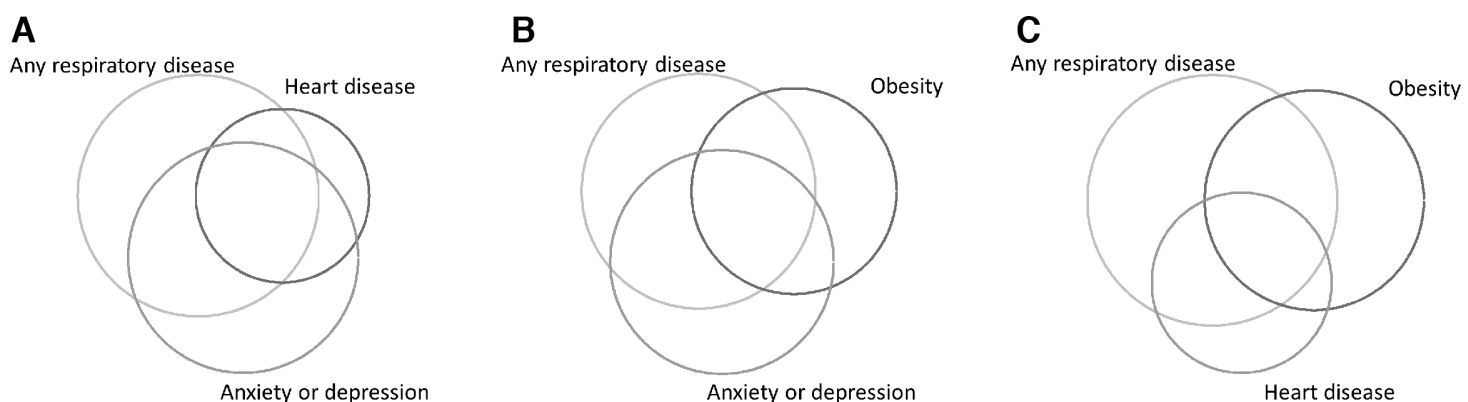

Figure 1 (A) Overlap between respiratory disease, heart disease or chest pain and anxiety or depression among participants reporting breathlessness (score $\geq 1$ on the modified Medical Research Council scale), $n=108$. Respiratory disease ( $\mathrm{n}=58$ ) is defined as self-reported disease and/or presence of pathology on spirometry, heart disease or chest pain ( $n=35$ ) is selfreported previous disease, self-reported angina or atrial fibrillation on ECG, anxiety or depression $(n=56)$ is either self-reported symptoms of depression or of anxiety. (B) Overlap between respiratory disease, obesity and anxiety or depression among participants reporting breathlessness (score $\geq 1$ on the modified Medical Research Council scale), $n=108$. Obesity ( $=43$ ) is defined as a body mass index $>30$. (C) Overlap between respiratory disease, obesity and heart disease or chest pain among participants reporting breathlessness (score $\geq 1$ on the modified Medical Research Council scale), $n=108$. heart disease or chest pain $(n=35)$ is defined as self-reported previous disease, self-reported angina or atrial fibrillation on ECG.

Chronic bronchitis was found to be independently associated with breathlessness. The same trend has been observed elsewhere. ${ }^{53} 54$ One hypothesis for this is that among the individuals with symptoms of chronic bronchitis, there are individuals with normal spirometry but with chronic airway inflammation resulting in both symptoms of chronic bronchitis and increased risk for air trapping resulting in breathlessness during exercise as has been shown to be common among individuals with asymptomatic COPD. ${ }^{55}$

\section{Strengths and limitations}

Strengths of the present study include that the measurements used, such as mMRC, spirometry testing and aerobic fitness testing, have a high validity and are relevant and detailed. ${ }^{9}{ }^{14}$ The relationship between obesity and breathlessness was explored using additional data on aerobic fitness level, which has not been performed previously.

Potential limitations of the study include the relatively few cases of breathlessness in the population that were handled by analysing larger categories of possible underlying conditions to breathlessness. It would have been interesting to be able to also analyse the data using an ordinal regression analysis to explore the impact on breathlessness severity from the different conditions. Since the number of individuals on each individual mMRC level was low, the results were considered to be too imprecise. We hope that the present study can be of use as a foundation for more detailed analysis in future larger datasets. No data were available on intensity, multiple dimensions of breathlessness or symptom duration that would have strengthened the findings and given interesting information. Data on aerobic fitness were only available for a subcohort, which was unfortunate and a limitation to the study. There was also a known selection bias due to individuals with reports of obvious heart disease or taking beta-adrenergic blockers being excluded from aerobic fitness testing. However, it is probable that the excluded group would have a low fitness level due to their known illness. Another limitation was some uncertainty of the reliability of diagnoses that are part of the primary endpoints, mainly due to the use of self-report for main diagnoses.

\section{Implications}

This study reports the main underlying contributing conditions among individuals with breathlessness as well as the most common concurrent conditions in a sample of the middle-aged general population. The clinical evaluation of breathlessness in a population of unselected patients presenting with breathlessness, such as in primary care should focus on respiratory disease, anxiety or depression, obesity and heart disease. Future research is needed on this area using larger datasets and more detailed data to further explore the role of chronic bronchitis, angina pectoris, ischaemic heart disease, obesity and aerobic fitness to breathlessness.

\section{Conclusion}

The main underlying contributing conditions among individuals reporting breathlessness were respiratory disease $(54 \%)$ followed by anxiety or depression $(51 \%)$, obesity (43\%) and heart disease or chest pain $(32 \%)$. Overlap was common with $66 \%$ having two or more concurrent conditions. Independent associations with breathlessness were found for chronic bronchitis, asthma, angina pectoris, depression and obesity.

\footnotetext{
Author affiliations

${ }^{1}$ Faculty of Medicine, Department of Clinical Sciences Lund, Respiratory Medicine and Allergology, Lund University, Lund, Sweden

${ }^{2}$ Department of Molecular and Clinical Medicine, Sahlgrenska Academy, University of Gothenburg, Gothenburg, Sweden

${ }^{3}$ Sahlgrenska University Hospital/Östra, Gothenburg, Sweden
} 
${ }^{4}$ Center for Health and Performance, University of Gothenburg, Gothenburg, Sweden

${ }^{5}$ Department of Clinical Physiology, Region Västra Götaland, Sahlgrenska University Hospital, Gothenburg, Sweden

${ }^{6}$ Department of Cardiology, Sahlgrenska University Hospital, Gothenburg, Sweden

${ }^{7}$ Department of Occupational and Environmental Medicine, School of Public Health and Community Medicine, Institute of Medicine, Sahlgrenska Academy at University of Gothenburg, Gothenburg, Sweden

Contributors The authors confirm contribution to the paper as follows: study conception and design: all authors; data collection: $\mathrm{KT}, \mathrm{GB}, \mathrm{AR}$ and $\mathrm{MB}$; analysis and interpretation of results: all authors; draft manuscript preparation: JS. All authors reviewed the results and approved the final version of the manuscript.

Funding Wallenberg Foundation, the Swedish Research Council (VR), VINNOVA and the Swedish Council for Working Life, Health, and Welfare (FORTE). In addition, there was support from the Sahlgrenska University Hospital, strategic grants from ALF/LUA (Avtal om Läkarutbildning och Forskning) in Western Sweden and from the Sahlgrenska Academy at University of Gothenburg. JS was funded by an unrestricted grant from the Blekinge Council of Science. ME was supported by unrestricted grants from the Swedish Respiratory Society, the Swedish Heart-Lung Foundation and the Swedish Research Council (DNr: 2019-02081). AR is supported by AFA Insurance.

Competing interests None declared.

Patient and public involvement Patients and/or the public were not involved in the design, or conduct, or reporting, or dissemination plans of this research.

Patient consent for publication Not required.

Ethics approval The study was approved by the regional ethic committee of Umeå (DNr 2010/228-31) and Gothenburg (DNr 399-16). Written informed consent was provided by all participants.

Provenance and peer review Not commissioned; externally peer reviewed.

Data availability statement Data are available on reasonable request. Data cannot be made freely available as they are subject to secrecy in accordance with the Swedish Public Access to Information and Secrecy Act but can be made available to researchers upon request (subject to a review of secrecy). Requests for data should be made to the corresponding author of this paper. A prerequisite for access to data is a permission from a Swedish Ethical Committee. More information can be found at http://scapis.org/.

Open access This is an open access article distributed in accordance with the Creative Commons Attribution Non Commercial (CC BY-NC 4.0) license, which permits others to distribute, remix, adapt, build upon this work non-commercially, and license their derivative works on different terms, provided the original work is properly cited, appropriate credit is given, any changes made indicated, and the use is non-commercial. See: http://creativecommons.org/licenses/by-nc/4.0/.

ORCID iDs

Jacob Sandberg http://orcid.org/0000-0003-1863-2033

Magnus Ekström http://orcid.org/0000-0002-7227-5113

\section{REFERENCES}

1 Lopez Varela MV, Montes de Oca M, Halbert RJ, et al. Sex-Related differences in COPD in five Latin American cities: the PLATINO study. Eur Respir J 2010;36:1034-41.

2 Bowden JA, To THM, Abernethy AP, et al. Predictors of chronic breathlessness: a large population study. BMC Public Health 2011;11:33.

3 Grønseth R, Vollmer WM, Hardie JA, et al. Predictors of dyspnoea prevalence: results from the BOLD study. Eur Respir $J$ 2014;43:1610-20.

4 Stevens JP, Dechen T, Schwartzstein R, et al. Prevalence of dyspnea among hospitalized patients at the time of admission. $J$ Pain Symptom Manage 2018;56:15-22.

5 Frostad A, Søyseth V, Andersen A, et al. Respiratory symptoms as predictors of all-cause mortality in an urban community: a 30-year follow-up. J Intern Med 2006;259:520-9.

6 Pedersen F, Mehlsen J, Raymond I, et al. Evaluation of dyspnoea in a sample of elderly subjects recruited from general practice. Int $J$ Clin Pract 2007:61:1481-91.

7 Parshall MB, Schwartzstein RM, Adams L, et al. An official American thoracic Society statement: update on the mechanisms, assessment, and management of dyspnea. Am J Respir Crit Care Med 2012;185:435-52.

8 Celli BR, Cote CG, Marin JM, et al. The body-mass index, airflow obstruction, dyspnea, and exercise capacity index in chronic obstructive pulmonary disease. N Engl J Med 2004;350:1005-12.

9 Nishimura K, Izumi T, Tsukino M, et al. Dyspnea is a better predictor of 5-year survival than airway obstruction in patients with COPD. Chest 2002:121:1434-40.

10 Figarska SM, Boezen HM, Vonk JM. Dyspnea severity, changes in dyspnea status and mortality in the general population: the Vlagtwedde/Vlaardingen study. Eur J Epidemiol 2012;27:867-76.

11 Santos M, Kitzman DW, Matsushita K, et al. Prognostic importance of dyspnea for cardiovascular outcomes and mortality in persons without prevalent cardiopulmonary disease: the Atherosclerosis risk in Communities study. PLoS One 2016;11:e0165111.

12 Pesola GR, Ahsan H. Dyspnea as an independent predictor of mortality. Clin Respir J 2016;10:142-52.

13 Stavem K, Sandvik L, Erikssen J. Breathlessness, phlegm and mortality: 26 years of follow-up in healthy middle-aged Norwegian men. J Intern Med 2006;260:332-42.

14 Sandberg J, Engström G, Ekström M. Breathlessness and incidence of COPD, cardiac events and all-cause mortality: a 44-year follow-up from middle age throughout life. PLoS One 2019;14:e0214083.

15 Pratter MR, Abouzgheib W, Akers S, et al. An algorithmic approach to chronic dyspnea. Respir Med 2011;105:1014-21.

16 O'Donnell DE, Milne KM, James MD, et al. Dyspnea in COPD: new mechanistic insights and management implications. Adv Ther 2020;37:41-60

17 Pratter MR, Curley FJ, Dubois J, et al. Cause and evaluation of chronic dyspnea in a pulmonary disease clinic. Arch Intern Med 1989;149:2277-82.

18 Ekström MP, Blomberg A, Bergström G, et al. The association of body mass index, weight gain and central obesity with activityrelated breathlessness: the Swedish cardiopulmonary Bioimage study. Thorax 2019;74:958-64.

19 Bernhardt V, Wood HE, Moran RB, et al. Dyspnea on exertion in obese men. Respir Physiol Neurobiol 2013;185:241-8.

20 Babb TG, Ranasinghe KG, Comeau LA, et al. Dyspnea on exertion in obese women: association with an increased oxygen cost of breathing. Am J Respir Crit Care Med 2008:178:116-23.

21 Parshall MB, Schwartzstein RM, Adams L, et al. An official American thoracic Society statement: update on the mechanisms, assessment, and management of dyspnea. Am J Respir Crit Care Med 2012;185:435-52.

22 Gaspard D, Kass J, Akers S, et al. Patient-Reported dyspnea correlates poorly with aerobic exercise capacity measured during cardiopulmonary exercise testing. Lung 2017;195:613-7.

23 Chan P-YS, von Leupoldt A, Bradley MM, et al. The effect of anxiety on respiratory sensory gating measured by respiratory-related evoked potentials. Biol Psychol 2012;91:185-9.

24 Johnson MJ, Bowden JA, Abernethy AP, et al. To what causes do people attribute their chronic breathlessness? A population survey. $J$ Palliat Med 2012;15:744-50.

25 Cavaillès A, Brinchault-Rabin G, Dixmier A, et al. Comorbidities of COPD. Eur Respir Rev 2013;22:454-75.

26 Bergström G, Berglund G, Blomberg A, et al. The Swedish cardiopulmonary Biolmage study: objectives and design. $J$ Intern Med 2015;278:645-59.

27 Torén K, Olin A-C, Lindberg A, et al. Vital capacity and COPD: the Swedish cardiopulmonary biolmage study (SCAPIS). Int J Chron Obstruct Pulmon Dis 2016;11:927-33.

28 Schilling RS, Hughes JP, Dingwall-Fordyce I. Disagreement between observers in an epidemiological study of respiratory disease. Br Med $J$ 1955;1:65-8.

29 Bestall JC, Paul EA, Garrod R, et al. Usefulness of the medical Research Council (MRC) dyspnoea scale as a measure of disability in patients with chronic obstructive pulmonary disease. Thorax 1999;54:581-6.

30 Hess MW. The 2017 global initiative for chronic obstructive lung disease report and practice implications for the respiratory therapist. Respir Care 2017;62:1492-500.

31 Miller MR, Hankinson J, Brusasco V, et al. Standardisation of spirometry. Eur Respir J 2005;26:319-38.

32 Brisman J, Kim J-L, Olin A-C, et al. A physiologically based model for Spirometric reference equations in adults. Clin Physiol Funct Imaging 2016;36:77-84

33 Hedenström H, Malmberg P, Agarwal K. Reference values for lung function tests in females. regression equations with smoking variables. Bull Eur Physiopathol Respir 1985;21:551-7. 
34 Hedenström H, Malmberg P, Fridriksson HV. Reference values for lung function tests in men: regression equations with smoking variables. Ups J Med Sci 1986;91:299-310.

35 Salorinne Y. Single-Breath pulmonary diffusing capacity. reference values and application in connective tissue diseases and in various lung diseases. Scand J Respir Dis Suppl 1976;96:1-84.

36 Pellegrino R, Viegi G, Brusasco V, et al. Interpretative strategies for lung function tests. Eur Respir J 2005;26:948-68.

37 Björkman F, Ekblom-Bak E, Ekblom Örjan, et al. Validity of the revised Ekblom Bak cycle ergometer test in adults. Eur J Appl Physiol 2016;116:1627-38.

38 Ekblom-Bak E, Björkman F, Hellenius M-L, et al. A new submaximal cycle ergometer test for prediction of VO2max. Scand J Med Sci Sports 2014;24:319-26.

39 Rosengren A, Hawken S, Ônpuu S, et al. Association of psychosocial risk factors with risk of acute myocardial infarction in 11119 cases and 13648 controls from 52 countries (the INTERHEART study): casecontrol study. The Lancet 2004;364:953-62.

40 Patten SB. Performance of the composite international diagnostic interview short form for major depression in community and clinical samples. Chronic Dis Can 1997;18:109-12.

41 WHO. Haemoglobin concentrations for the diagnosis of anaemia and assessment of severity. vitamin and mineral nutrition information system, 2011.

42 Ekström M, Schiöler L, Grønseth R, et al. Absolute values of lung function explain the sex difference in breathlessness in the general population. Eur Respir J 2017;449:1602047.

43 Sundh J, Ekström M. Persistent disabling breathlessness in chronic obstructive pulmonary disease. Int $J$ Chron Obstruct Pulmon Dis 2016;11:2805-12.

44 Punekar YS, Mullerova $\mathrm{H}$, Small M, et al. Prevalence and burden of dyspnoea among patients with chronic obstructive pulmonary disease in five European countries. Pulmonary Therapy 2016;2:59-72
45 Müllerová $\mathrm{H}, \mathrm{Lu} \mathrm{C}, \mathrm{Li} \mathrm{H}$, et al. Prevalence and burden of breathlessness in patients with chronic obstructive pulmonary disease managed in primary care. PLoS One 2014;9:e85540.

46 Smith AK, Currow DC, Abernethy AP, et al. Prevalence and outcomes of breathlessness in older adults: a national population study. J Am Geriatr Soc 2016;64:2035-41.

47 Ekström M, Currow DC, Moens K. Symptom patterns in populations. In: Bausewein C, Johnson MJ, Currow DC, eds. ERS monograph of palliative care. European Respiratory Society, 2016.

48 Gong W, Ostermann J. PVENN: Stata module to create proportional Venn diagram, 2011.

49 Sandberg J, Ekström M. Differences between experienced and recalled breathlessness. Curr Opin Support Palliat Care 2019;Publish Ahead of Print:161-6.

50 Neuman A, Gunnbjörnsdottir M, Tunsäter A, et al. Dyspnea in relation to symptoms of anxiety and depression: a prospective population study. Respir Med 2006;100:1843-9.

51 ten Thoren C, Petermann F. Reviewing asthma and anxiety. Respir Med 2000;94:409-15.

52 Ekblom-Bak E, Olsson G, Ekblom Örjan, et al. The daily movement pattern and Fulfilment of physical activity recommendations in Swedish middle-aged adults: the SCAPIS pilot study. PLoS One 2015;10:e0126336

53 Ekström M, Sundh J, Schiöler L, et al. Absolute lung size and the sex difference in breathlessness in the general population. PLoS One 2018;13:e0190876.

54 Mejza F, Gnatiuc L, Buist AS, et al. Prevalence and burden of chronic bronchitis symptoms: results from the BOLD study. Eur Respir $J$ 2017;50:1700621.

55 Soumagne T, Laveneziana P, Veil-Picard M, et al. Asymptomatic subjects with airway obstruction have significant impairment at exercise. Thorax 2016;71:804-11. 